
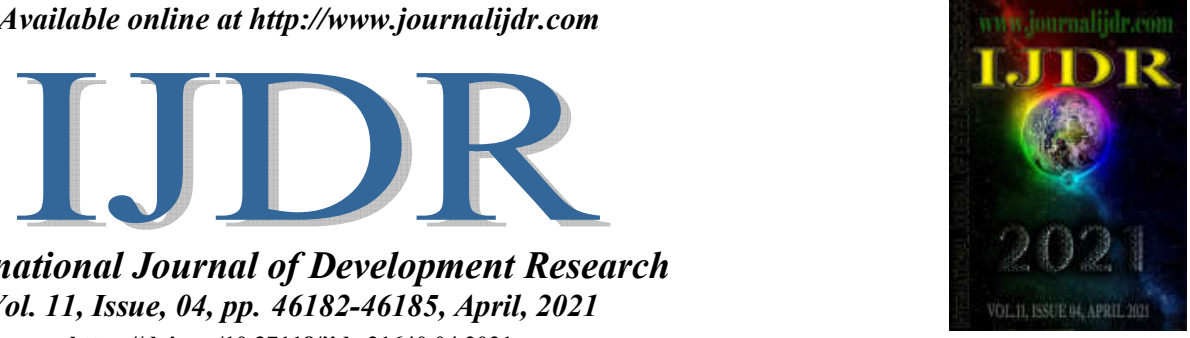

ISSN: 2230-9926

International Journal of Development Research

Vol. 11, Issue, 04, pp. 46182-46185, April, 2021

https://doi.org/10.37118/ijdr.21640.04.2021

\title{
ESPIRITUALIDADE E RELIGIOSIDADE NO AMBIENTE ACADÊMICO
}

\section{Cynthia Kallás Bachur ${ }^{1,}{ }^{*}$, Geisa Ribeiro Borges², RayssaSawan Mendonça², Laurynês de Castro², Sarah da Silva Candido ${ }^{3}$}

\author{
1Fisioterapeuta, Doutora, Docente nos cursos de Fisioterapia e de Medicina da Universidade de Franca, \\ Franca - S.P. - Brasil \\ 2Estudantes do curso de Medicina da Universidade de Franca - S.P. - Brasil \\ ${ }^{3}$ Fisioterapeuta. Docente e Supervisora do Curso de Fisioterapia da Universidade de \\ Franca -Franca - S.P. - Brasil
}

\begin{tabular}{l} 
ARTICLE INFO \\
\hline Article History: \\
Received $12^{\text {th }}$ January, 2021 \\
Received in revised form \\
$09^{\text {th }}$ February, 2021 \\
Accepted $19^{\text {th }}$ March, 2021 \\
Published online $22^{\text {th }}$ April, 2021 \\
\hline
\end{tabular}

Key Words:

Estudantes; Espiritualidade; Qualidade de vida; Autocuidado.

*Corresponding author:

Cynthia Kallás Bachur

\begin{abstract}
RESUMO
Objetivo: identificar se religiosidade e espiritualidade são preditoras de qualidade de vida entre universitários. Métodos: estudo exploratório, descritivo e transversal realizado em uma instituição de ensino superior privada, de 2019 a 2020. Amostra por conveniência, composta de estudantes de medicina. Aplicou-se dois questionários, o sociodemográfico e o questionário WHOQOL-SRPB, queavalia a qualidade de vida, composto por 32 itens e 8 facetas: conexão a ser ou força espiritual, sentido da vida, admiração, totalidade e integração, força espiritual, paz interior, esperança e otimismo e fé. As respostas foram baseadas na Escala Likert de 5 pontos $(1=$ nada e 5 = completamente). Resultados: 271 estudantes, idade média de $21,79 \pm 2$,83anos. A menor pontuação, 28 (10,3\%) foi na questão: "Até que ponto alguma ligação a um ser espiritual ajuda você a tolerar o estresse?" "e $41(15,1 \%)$ indicaram pontuação '2' ou "Muito pouco". A maior pontuação, diz respeito ao Sentido na Vida, com 145 (53,5\%) estudantes alegando que cuidar de outras pessoas proporciona um sentido na vida "Completamente". Conclusão: a religiosidade e a espiritualidade podem estar relacionadas a qualidade de vida dos estudantes do curso de medicina e deve ser abordada como uma forma de autocuidado e para com o próximo.
\end{abstract}

Copyright (C) 2021, Cynthia Kallás Bachur et al. This is an open access article distributed under the Creative Commons Attribution License, which permits unrestricted use, distribution, and reproduction in any medium, provided the original work is properly cited.

Citation: Cynthia Kallás Bachur, Geisa Ribeiro Borges, RayssaSawan Mendonça, Laurynês de Castro, Sarah da Silva Candido. "Espiritualidade e religiosidade no ambiente acadêmico", International Journal of Development Research, 11, (04), 46182-46185.

\section{INTRODUÇÃO}

A espiritualidade está relacionada a alguma crença ou fé que as pessoas atribuem em alguma religião ou entidade espiritual e, não necessariamente a uma religião especifica, mas sim na crença e fé em uma força divina. Há disponível na literatura estudos que buscam explicar as influências da espiritualidade na saúde e tem-se observado seus benefícios na melhora clínica de pessoas enfermas durante o tratamento ou em situações de pressão extrema, como acadêmicos em formação (Whoqol, 2006). Acredita-se que na maioria das crenças há um grande cuidado com o corpo, o qual é visto como um templo na maioria das religiões. Esta atitude ou pensamento tem levado o ser na busca constante do equilíbrio, ajudando a "afastar" doenças e enfermidades (Boff, 2006). A religiosidade traz a criação de grupos de interesse em comum, formando um círculo de amizade que acaba por se transforma em um suporte humano, que através da confiança e da liberdade, a pessoa passa expressar sentimentos e dificuldades enfrentadas (Puchalski, 2009). A Organização Mundial de Saúde definesaúde como o estado de completo bem-estar físico, mental, espiritual e social e não apenas a ausência de doença ou enfermidade (OMS, 1946). Nos últimos 20 anos, a temática ganha destaque devido à influência da Espiritualidade, gerando estudos internacionais e nacionais para contribuir com formação acadêmica e científica (Murakami, 2012). A religiosidade no Brasil possui um grande marco ao longo da história, tornando-se uma ótima ferramenta que facilita atributos direcionados ao ato do cuidar (Vasconcelos, 2009). Pode-se observar que há uma dificuldade por parte dos profissionais no que diz respeito à religiosidade e suas práticas, pois não obtiveram ensinamentos corretos sobre a temática em suas formações (Gobatto, 2013). A introdução da espiritualidade na vida acadêmica e até mesmona vida pessoal para o autoconhecimento e equilíbrio da mente, tem demonstrado melhores resultados na relação médicopaciente e adesão do paciente ao tratamento. 
Com isso, o acadêmico direciona seus trabalhos cotidianos, suas pesquisas e principalmente atribui significados a vida (Alves, 2010; Tartaro, 2005). As crenças e orações trazem conforto emocional e equilíbrio psicológico, promovem outra percepção das doenças, trazendo uma melhora a saúde e ajudando em sua manutenção (Alves, 2010). A prática da espiritualidade, por meio de preces, orações ou meditações, está intimamente relacionada à diminuição do cortisol, menores níveis glicêmicos, frequência respiratória e arterial (Tartaro, 2005; Holt-Lunstad, 2011). O estudante deve buscar ao máximo conhecer tal temática, para que possa aceitar e respeitar a individualidade religiosa de cada um, usando como complemento de seu trabalho todos os recursos válidos para promoção do bem-estar de seus pacientes, mas principalmente no seu equilíbrio emocional para uma formação integral e um exercício efetivo (Moreira-Almeida, 2006). Para avaliar a qualidade de vida (QV) dos estudantes, encontrou-se na literatura um questionário World Health Organization Qualityof Life (WHOQOL-SRPB) que possibilita identificar a espiritualidade, a religião e as crenças pessoais e permite correlacionar com a saúde, que busca compreender como a crença ajuda a resolver seus problemas, entender como reflete tal tema na sua qualidade de vida e como influência no comportamento humano. Este instrumento é um constructo usado em consideração ao equilíbrio psíquico e bem estar e é considerada uma ferramenta genuína da transculturalidade tornando-se relevante para as pesquisas e pode contribuir nos estudos para explicar a interação da espiritualidade com a saúde (Flecka, 2003). A religiosidade na vida acadêmica é uma forma de preparar o profissional para ser um suporte mais completo de seus pacientes. Mas, para que o acadêmico consiga esse comportamento é necessário uma boa formação e conhecimento do que será colocado em prática. Desta forma, surge à necessidade dos cursos da área da saúde se voltarem para um atendimento mais humanizado, buscando compreender de forma abrangente o ser para adquirir uma visão integral e suas múltiplas dimensões para atender suas necessidades. Oobjetivo deste estudo foi identificar se a religiosidade e a espiritualidade são preditoras de qualidade de vida entre estudantes universitários.

\section{MÉTODOS}

Trata-se de um estudo exploratório, descritivo e transversal, realizado em uma universidade privado de uma cidade no interior do estado de São Paulo, durante o ano de 2019 e 2020 .A população alvo proposta para este estudo foram estudantes do curso de medicina e a amostra foi por conveniência. Aplicou-se um questionário sócio demográfico, incluindo as variáveis sexo, idade, estado civil e frequência de presença no serviço religioso e oquestionário WHOQOL$S R P B$ módulo espiritualidade, religiosidade e crenças pessoais, composto por 32 itens e 8 facetas: conexão a ser ou força espiritual, sentido da vida, admiração, totalidade e integração, força espiritual, paz interior, esperança e otimismo e fé ${ }^{14}$. As respostas foram baseadas na Escala Likert de 5 pontos, em que $1=$ nada; $2=$ muito pouco; $3=$ médio; $4=$ muitoe $5=$ completamente. Os critérios de inclusão utilizados foram estudantes regularmente matriculados do primeiro ao terceiro ano do curso de medicina e idade superior a 18 anos, e como critériode exclusão arecusa em participar do projeto. A metodologia da análise de dados foi a partir do programa Access for Windows 2010, contemplando todas as variáveis da pesquisa. Os dados receberam tratamento estatístico através do software SPSS 17.0, com abordagem inicial a estatística descritiva com a distribuição de frequências simples e relativa. Este estudo foi aprovado pelo comitê de ética CAAE 20602519.1.0000.5495 e todos os participantes, após concordância, assinaram o Termo de Consentimento Livre e Esclarecido, seguindo os preceitos éticos.

\section{RESULTADOS}

Participaram deste estudo 271 estudantes, com idade média de 21,79 \pm 2 ,83anos.A Tabela 1 apresenta a distribuição dos estudantes, de acordo com as características sócio-demográficas.
Com o propósito de avaliar a espiritualidade, religião e crenças pessoais, todos os estudantesresponderam ao instrumento WHOQOL$S R P B$. A Tabela 2 apresenta os resultados dos escores do questionário aplicado de acordo com a etapa de cada faceta apresentada. Ao avaliar a espiritualidade, religião e crenças pessoais dos estudantes de medicina, foi possível identificar médias similaresentre as facetas analisadas. No entanto, algumas específicas abordagens tiveram destaque por apresentarem baixos escores. Considerando a maior frequência dentro da menor pontuação $(1=$ nada), $28(10,3 \%)$ estudantes indicaram valor '1' para a seguinte questão: "Até que ponto alguma ligação a um ser espiritual ajuda você a tolerar o estresse?" e $41(15,1 \%)$ indicaram pontuação ' 2 ' ou seja, "Muito pouco". A maior frequência dentro da maior pontuação, diz respeito ao Sentido na Vida, em que145 (53,5\%) estudantes alegaram que cuidar de outras pessoas proporciona um sentido na vida "Completamente". Respectivamente dentro de outro domínio, na faceta "Admiração", 108 (40\%) estudantes referiram estar agradecidos por poder apreciar as coisas da natureza, e referente à questão: "Até que ponto ser otimista melhora a sua qualidade de vida?"100 (45,2\%) responderam "Muito" e 71 (32,1\%) "Completamente". De modo global, os participantes do presente estudo, apresentaram resultados em sua maioria no nível "Médio".

\section{DISCUSSÃO}

Muito tem sido falado sobre a QVe saúde mental dos estudantes do curso de medicina e, de acordo com dados do Conselho Federal de Medicina (CFM), mais da metade dos médicos do Brasil apresentam algum tipo de distúrbio psiquiátrico, sendo a ansiedade e a depressão os principais (Borges, 2013). Este conselho demonstrou que em torno de $5 \%$ dos profissionais médicos se sentem sem esperança, infelizes e apresentam ideias suicidas. Dentre os principais fatores apontados como desencadeantes para a redução na qualidade de vida desses estudantes e profissionais, temos: a alta carga horária, a grande quantidade de conteúdo para ser aprendida em curto período de tempo, a pressão e cobrança dentro e fora do meio acadêmico, a falta de tempo para realizar atividades extracurriculares, o pouco convívio social, o contato frequente com doentes graves e com a morte (Lacombe, 2017). Estudorealizado para avaliar a QV de estudantes e profissionais médicos, aplicou-se o questionário $W H O Q O L-B R E F \mathrm{em}$ 564 estudantes matriculados entre o primeiro e oitavo semestre do curso de medicina, e a maioria dos fatores estressantes que resultam em baixa QV, sendo que 73,2\% relataram falta de tempo, $40 \%$ já haviam pensado ou ainda tinha em mente a ideia de abandonar o curso em decorrência da sobrecarga, a qual foi referida por $49,5 \%$ dos estudantes. Sobre a vida, $30 \%$ disseram aproveitar nada ou muito pouco e $5 \%$ responderam que não têm sentido na vida. Além disso, $56,4 \%$ deles tinham sentimentos negatives (Gonçalves, 2013. Sabe-se que a QV e a saúde mental estão intimamente relacionadas com a espiritualidade, pois quando abordada em pacientes enfermos o resultado físico e psicossocial apresenta considerável melhora, quando comparado naqueles que não possuem algum tipo de fé (Sousa, 2019).

No presente estudo identificou-se que $68,6 \%$ dos estudantes têm freqüência na religiosidade inferior a uma vez no mês e, quando questionados sobre fé e espiritualidade, menos de $40 \%$ dos participantes possuem algum tipo de crença e, no tópico "paz interior", a maioria respondeu "médio" para as 4 perguntas. Esses resultados podem ser comparados com um estudo realizado com 210 estudantes de medicina do $1^{\circ}$ ao $6^{\circ}$ da Faculdade de Medicina de Jundiaí, utilizando perguntas da escala de religiosidade da DukeDUREL. Nele, foi identificado que apenas $21,2 \%$ dos participantes freqüentavam serviços religiosos pelo menos uma vez na semana, $38,8 \%$ dedicavam o seu tempo a atividades religiosas ou individuais (preces, rezas, meditações, leitura de livros/textos religiosos) diariamente e, 73,9\% eram afiliados de alguma religião. Entretanto, ao quantificar as respostas sobre a relação entre a espiritualidade e a saúde, em torno de $68 \%$ não correlacionam esses dois temas (Borges, 2013). 
Tabela 1.Distribuição absoluta e relativa dos estudantes de medicina, quanto às características sociodemográficase frequência de religiosidade, divididos por sexo, 2019-2020

\begin{tabular}{|l|l|l|l|l|l|l|}
\hline & \multicolumn{2}{|l|}{$\begin{array}{l}\text { Feminino } \\
\mathrm{n}=192\end{array}$} & \multicolumn{2}{l|}{$\begin{array}{l}\text { Masculino } \\
\mathrm{n}=79\end{array}$} & \multicolumn{2}{l|}{$\begin{array}{l}\text { Total } \\
\mathrm{n}=271\end{array}$} \\
\hline Turma & $\mathrm{n}$ & $\%$ & $\mathrm{n}$ & $\%$ & $\mathrm{n}$ & $\%$ \\
\hline $1^{\circ}$ ano & 30 & 15,6 & 17 & 21,5 & 47 & 17,3 \\
\hline $2^{\circ}$ ano & 73 & 38 & 31 & 39,2 & 104 & 38,3 \\
\hline $3^{\circ}$ ano & 89 & 46,3 & 31 & 39,2 & 120 & 44,2 \\
\hline Total & 192 & 100 & 79 & 100 & 271 & 100 \\
\hline Estado Civil & & & & & & \\
\hline Solteiro & 188 & 97,9 & 78 & 98,7 & 266 & 98,1 \\
\hline Casado & 4 & 2 & 1 & 1,2 & 5 & 1,84 \\
\hline Total & 192 & 100 & 79 & 100 & 271 & 100 \\
\hline Frequência religiosidade & & & & & & \\
\hline$\leq 1$ vez ao mês & 128 & 66,6 & 58 & 73,4 & 186 & 68,6 \\
\hline 1 vez por semana & 56 & 29,1 & 17 & 21,5 & 73 & 26,9 \\
\hline Mais de 1 vez por semana & 4 & 2 & 1 & 1,2 & 5 & 1,84 \\
\hline Nunca & 0 & 0 & 1 & 1,2 & 1 & 0,36 \\
\hline Sem resposta & 4 & 2 & 2 & 2.5 & 6 & 2,21 \\
\hline Total & 192 & 100 & 79 & 100 & 271 & 100 \\
\hline
\end{tabular}

Tabela 2. Distribuição absoluta e relativadas respostas referente àsfacetas avaliadas pelo WHOQOL-SRPB em estudantes do curso de Medicina, Franca, 2019-2020

\begin{tabular}{|c|c|c|c|c|c|c|c|c|c|c|c|c|}
\hline \multirow[b]{2}{*}{ FACETAS } & \multicolumn{2}{|c|}{ Nada } & \multicolumn{2}{|c|}{ Muito pouco } & \multicolumn{2}{|c|}{ Médio } & \multicolumn{2}{|c|}{ Muito } & \multicolumn{2}{|c|}{ Completamente } & \multicolumn{2}{|c|}{ Total } \\
\hline & $\mathbf{n}$ & $\%$ & $\mathbf{n}$ & $\%$ & n & $\%$ & $\mathbf{n}$ & $\%$ & $\mathbf{n}$ & $\%$ & n & $\%$ \\
\hline \multicolumn{13}{|l|}{ CONEXÃO A SER OU FORÇA ESPIRITUAL } \\
\hline $\begin{array}{l}\text { Até que ponto alguma ligação a um ser espiritual ajuda você a } \\
\text { passar por épocas difíceis? }\end{array}$ & 20 & 7,38 & 15 & 5,53 & 55 & 20,2 & 90 & 33,2 & 91 & 33,5 & 271 & 10 \\
\hline $\begin{array}{l}\text { Até que ponto alguma ligação a um ser espiritual ajuda você a } \\
\text { tolerar o estresse? }\end{array}$ & 28 & 10,3 & 41 & 15,1 & 74 & 27,3 & 73 & 26,9 & 55 & 20,2 & 271 & 10 \\
\hline $\begin{array}{l}\text { Até que ponto alguma ligação com um ser espiritual ajuda você a } \\
\text { compreender os outros? }\end{array}$ & 23 & 8,4 & 31 & 11,4 & 72 & 26,5 & 83 & 30,6 & 62 & 22,8 & 271 & 10 \\
\hline $\begin{array}{l}\begin{array}{l}\text { Até que ponto alguma ligação } \\
\text { conforta/tranquiliza você? }\end{array} \\
\text { com um ser espiritual } \\
\end{array}$ & 17 & 6,2 & 19 & 7 & 46 & 16,9 & 82 & 30,2 & 107 & 39,4 & 271 & 10 \\
\hline \multicolumn{13}{|l|}{ SENTIDO NA VIDA } \\
\hline Até que ponto você encontra um sentido na vida? & 2 & 0,73 & 8 & 2,9 & 64 & 23,6 & 108 & 39,8 & 89 & 32,8 & 271 & 100 \\
\hline $\begin{array}{l}\text { Até que ponto cuidar de outras pessoas proporciona um sentido na } \\
\text { vida para você? }\end{array}$ & 0 & 0 & 2 & 0,7 & 16 & 5,9 & 108 & 39,8 & 145 & 53,5 & 271 & 100 \\
\hline Até que ponto você sente que a sua vida tem uma finalidade? & 3 & 1,1 & 8 & 2,9 & 47 & 17,4 & 110 & 40,7 & 102 & 33,7 & 270 & 99,6 \\
\hline Até que ponto você sente que está aqui por um motivo? & 7 & 2,5 & 9 & 3,3 & 43 & 15,8 & 96 & 35,4 & 116 & 42,8 & 271 & 100 \\
\hline \multicolumn{13}{|l|}{ ADMIRAÇÃO } \\
\hline $\begin{array}{l}\text { Até que ponto você consegue ter admiração pelas coisas a seu } \\
\text { redor? (por exemplo: natureza, arte, música) }\end{array}$ & 0 & 0 & 4 & 1,4 & 48 & 17,8 & 114 & 42,3 & 103 & 38,2 & 269 & 99,2 \\
\hline Até que ponto você se sente espiritualmente tocado pela beleza? & 8 & 2,9 & 26 & 9,6 & 86 & 31,8 & 97 & 35,9 & 53 & 19,6 & 270 & 99,6 \\
\hline $\begin{array}{l}\text { Até que ponto você tem sentimentos de inspiração (emoção) na sua } \\
\text { vida? }\end{array}$ & 1 & 0,3 & 11 & 4 & 73 & 27 & 113 & 41,8 & 72 & 26,6 & 270 & 99,6 \\
\hline $\begin{array}{l}\text { Até que ponto você se sente agradecido por poder apreciar (“curtir") } \\
\text { as coisas da natureza? }\end{array}$ & 1 & 0,3 & 7 & 2,5 & 60 & 22,2 & 94 & 34,8 & 108 & 40 & 270 & 99,6 \\
\hline \multicolumn{13}{|l|}{ TOTALIDADE E INTEGRAÇÃO } \\
\hline $\begin{array}{l}\text { Até que ponto você sente alguma ligação entre a sua mente, corpo e } \\
\text { alma? }\end{array}$ & 2 & 0,7 & 8 & 2,9 & 72 & 26,6 & 114 & 42,2 & 74 & 27,4 & 270 & 99,6 \\
\hline $\begin{array}{l}\text { Quão satisfeito você está por ter um equilíbrio entre a mente, o } \\
\text { corpo e a alma? }\end{array}$ & 9 & 3,3 & 35 & 12,9 & 97 & 35,9 & 85 & 31,4 & 44 & 16,2 & 270 & 99,6 \\
\hline $\begin{array}{l}\text { Até que ponto você sente que a maneira em que vive está de acordo } \\
\text { com o que você sente e pensa? }\end{array}$ & 5 & 1,8 & 33 & 12,2 & 117 & 43,3 & 84 & 31,1 & 31 & 11,4 & 270 & 99,6 \\
\hline $\begin{array}{l}\text { Quanto as suas crenças ajudam-no a criar uma coerência (harmonia) } \\
\text { entre o que você faz, pensa e sente? }\end{array}$ & 8 & 3 & 22 & 8,2 & 68 & 25,5 & 116 & 43,6 & 54 & 20,3 & 266 & 98,1 \\
\hline \multicolumn{13}{|l|}{ FORÇA ESPIRITUAL } \\
\hline Até que ponto você sente força espiritual interior? & 8 & 3,3 & 25 & 10,5 & 81 & 34,1 & 74 & 31,2 & 49 & 20,6 & 237 & 87,4 \\
\hline $\begin{array}{l}\text { Até que ponto você pode encontrar força espiritual em épocas } \\
\text { difíceis? }\end{array}$ & 9 & 4 & 16 & 7,1 & 77 & 34,5 & 74 & 33,1 & 47 & 21 & 223 & 82,2 \\
\hline Quanto a força espiritual o ajuda a viver melhor? & 12 & 5,4 & 15 & 6,7 & 57 & 25,7 & 84 & 38 & 53 & 23,9 & 221 & 81,5 \\
\hline Até que ponto a sua força espiritual o ajuda a se sentir feliz na vida? & 11 & 5 & 17 & 7,7 & 63 & 28,6 & 78 & 35,4 & 51 & 23,1 & 220 & 81,1 \\
\hline \multicolumn{13}{|l|}{ PAZ INTERIOR } \\
\hline Até que ponto você se sente em paz consigo mesmo? & 2 & 0,9 & 16 & 7,2 & 93 & 42 & 85 & 38,4 & 25 & 11,3 & 221 & 81,5 \\
\hline Até que ponto você tem paz interior? & 4 & 1,7 & 16 & 7,1 & 101 & 45,2 & 75 & 33,6 & 25 & 11,2 & 223 & 82,2 \\
\hline Quanto você consegue sentir paz quando você necessita disso? & 1 & 0,4 & 33 & 14,9 & 95 & 42,9 & 72 & 32,5 & 20 & 9 & 221 & 81,5 \\
\hline Até que ponto você sente um senso de harmonia na sua vida? & 0 & 0 & 20 & 9 & 91 & 41,1 & 86 & 38,9 & 24 & 10,8 & 221 & 81,5 \\
\hline \multicolumn{13}{|l|}{ ESPERANÇA \& OTIMISMO } \\
\hline Quão esperançoso você se sente? & 1 & 0,4 & 15 & 6,8 & 74 & 33,6 & 94 & 42,7 & 36 & 16,3 & 220 & 81,1 \\
\hline Até que ponto você está esperançoso com a sua vida? & 1 & 0,4 & 17 & 7,6 & 54 & 24,4 & 109 & 49,3 & 40 & 18 & 221 & 81,5 \\
\hline Até que ponto ser otimista melhora a sua qualidade de vida? & 3 & 1,3 & 9 & 4 & 38 & 17,1 & 100 & 45,2 & 71 & 32,1 & 221 & 81,5 \\
\hline $\begin{array}{l}\text { Quanto você é capaz de permanecer otimista em épocas de } \\
\text { incerteza? }\end{array}$ & 5 & 2,2 & 42 & 19 & 97 & 43,8 & 61 & 27,6 & 16 & 7,2 & 221 & 81,5 \\
\hline \multicolumn{13}{|l|}{ FÉ } \\
\hline Até que ponto a fé contribui para o seu bem-estar? & 15 & 6,7 & 15 & 6,7 & 49 & 22,1 & 87 & 39,3 & 55 & 24,8 & 221 & 81,5 \\
\hline Até que ponto a fé lhe dá conforto no dia-a-dia? & 15 & 6,7 & 19 & 8,5 & 51 & 23 & 83 & 37,5 & 53 & 23,9 & 221 & 81,5 \\
\hline Até que ponto a fé lhe dá força no dia-a-dia? & 15 & 6,7 & 17 & 7,6 & 57 & 25,7 & 74 & 33,4 & 58 & 26,2 & 221 & 81,5 \\
\hline Até que ponto a fé o ajuda a gozar (aproveitar) a vida? & 16 & 7,2 & 22 & 9,9 & 58 & 26,2 & 79 & 35,7 & 46 & 20,8 & 221 & 81,5 \\
\hline
\end{tabular}


Em internos e residentes do curso de medicina e residentes, aplicou-se o questionário WHOQOL-SRPB em uma amostra de 114 participantes. O domínio com a menor média obtida foi o da $F e ́$ e, a maior, o do Sentido da Vida e os domínios que obtiveram menor e maior média de um modo geral foram Paz Interior e Admiração, respectivamente (Sousa, 2019). No presente estudo, 36,48\% e 38,93\% da amostraresponderam, "MUITO" para as perguntas da faceta Fée Sentido da Vida, respectivamente, demonstrando uma proximidade entre os resultados. O curso de medicina proporciona diversos fatores de risco para maiores situações de estresse, no qual está diretamente relacionado com os níveis de cortisol, proporcionando maior fragilidade do indivíduo a doenças, por ter efeito no sistema imune. A prática da espiritualidade pode ser um adicional no cotidiano dos estudantes em formação, pois traz benefícios tanto na saúde física como mental.Algumas universidades já adotaram a disciplina de Espiritualidade e Saúde nos currículoscomo uma disciplina optativa, como por exemplo, a Universidade Federal do Ceará, a Universidade de Medicina do Triangulo Mineiro e a Universidade Federal do Rio Grande do Norte. Sugere-se a possibilidade da oferta desta disciplina nos cursos de medicina como suporte na QV para os estudantes.

\section{CONCLUSÃO}

Com base nos resultados do presente estudo, sugere-se que a religiosidade e a espiritualidade podem estar relacionadas a qualidade de vida dos estudantes do curso de medicina, e que deve ser abordada como uma forma não somente de autocuidado, mas também para com o próximo.

Conflito de interesse: Os autores declaram não possuir conflitos de interesse na realização deste trabalho.

\section{REFERÊNCIAS}

WHOQOL SRPB Group. A cross-cultural study of spirituality, religion, and personal beliefs as components of quality of life.Social Science and Medicine. Soc Sci Med. 2006 Mar; 62(6): p. 1486-97.

Boff L. Espiritualidade: um caminho de transformação: Sextante; 2006.

Puchalski CM, MD, MS. Physicians and Patients' Spirituality: Ethical Concerns and Boundaries in Spirituality and Health. AMA Journal of Ethics. 2009 oct: p. 804-815.
OMS. Constituição da Organização Mundial da Saúde (OMS/WHO) 1946. [Online].; 1946 [cited 2019. Available from: http://www.direitoshumanos.usp.br/index.php/OMS-OrganizaçãoMundial-da-Saúde/constituicao-da-organizacao-mundial-dasaude-omswho.html.

Murakami R, Campos CJG. Religião e saúde mental: desafio de integrar a religiosidade ao cuidado com o paciente. Revista Brasileira de Enfermagem. 2012 Mar/Apr; 2(65): p. 361-367.

Vasconcelos EM. Espiritualidade na educação popular em saúde. Cadernos CEDES. 2009 sept/dec; 29(79): p. 323-334.

Gobatto CA, Araujo TCCFd. Religiosidade e espiritualidade em oncologia: concepções de profisssionais da saúde. Psicologia USP. 2013 Jan/Apr; 24(1): p. 11-34.

Alves RRdN, Alves HdN, Barboza RRD, Souto WdMS. The influence of religiosity on health. Ciência \& Saúde Coletiva. 2010 Jan/Jul; 15(4): p. 2105-2111.

Tartaro J, Luecken L, Gunn H. Exploring heart and soul: effects of religiosity/spirituality and gender on blood pressure and cortisol stress responses. J Health Psychol. 2005 Nov: p. 753 $\square 766$.

Holt-Lunstad J, Steffen P, Sandberg J, Jensen B. Understanding the connection between spiritual well-being and physical health: an examination of ambulatory blood pressure, inflammation, blood lipids and fasting glucose. J Behav Med. 2011 Dec: p. 477 $\square 488$.

Moreira-Almeida A, Koenig H. Retaining the meaning of the words religiousness and spirituality: a commentary on the WHOQOL SRPB group's "a cross-cultural study of spirituality, religion, and personal beliefs as components of quality of life". Soc Sci Med. 2006 Aug; 4(63): p. 843-5.

Flecka MPdA, Borgesb ZN, Bolognesia G, Rocha NSd. Development of WHOQOL spirituality, religiousness and personal beliefs module. Rev Saúde Pública. 2003; 4(37): p. 446-55.

Borges dC, Anjos GLd, Oliveira LRd, Leite JR, Lucchetti G. Saúde, espiritualidade e religiosidade na visão dos estudantes de medicina. Rev Bras Clin Med. 2013 jan-mar; 1(11): p. 6-11.

LACOMBE JB. Espiritualidade dos estudantes e residentes de medicina: associações com empatia e atitude na relação médicopaciente. Dissertação (Mestrado em Ciências da Saúde) Universidade Federal de Uberlândia. [Online].; 2017 [cited 2020 04 25. Available from: https://repositorio.ufu.br/ handle/ $123456789 / 21164$.

Gonçalves SS, Neto AMS. Dimensão psicológica da qualidade de vida de estudantes de medicina. Revista Brasileira de Educação Médica. 2013 July/Sept; 3(37): p. 385-395.

Sousa BSdA, Almeida MTdS, Almeida CAPL, Cruz JNd, Carvalho HEFd, Gonçalves LdA. Caracterização Sociodemográfica, Formação Acadêmica e índices de Religião e Espiritualidade de Docentes da Saúde. Rev Fund Care Online. 2019 Abril/Junho; 3(11): p. 672-679. 